\title{
PHYSICAL EXERCISES IN RELIEVING THE CURRENT STATE OF DEPRESSION
}

O EXERCÍCIO FÍSICO E O ALIVIO DE ESTADOS DE DEPRESSÃO ATIVA

Original Article

ARTIGo Original

ELEJERCICIO FÍSICO Y EL ALIVIO DEESTADOS DEDEPRESIÓN ACTIVA

Artículo Original

Linyan Dang 1 (D)

(Physical Education Professional)

1. College of Physical Education, Henan Finance University,

Zhengzhou, China.

\section{Correspondence}

Linyan Dang

Zhengzhou, China, 450046.

danglinyan2021@163.com

\begin{abstract}
Introduction: Physical exercise has become a common method at home and abroad as a means of psychotherapy and mental health. Objective: Observing the current situation and characteristics of physical exercise and depressive disorders and examining the influence of physical exercise on depressive disorders in the human body. Methods: The article compares and analyzes the relationship between human physical exercise and the level of depression and body self-esteem from the perspective of psychology. Results: The incidence of depression is higher. There are significant differences in the attitude towards physical exercise and the degree of depression in the three types of subjects in the study. Physical exercise is conducive to the relief of depression. Conclusion: Physical exercise is one of the effective ways to improve the depressive state of the human body. The effect of an exercise has no relation with the specific exercise method selected. Level of evidence Il; Therapeutic studies - investigation of treatment results.
\end{abstract}

Keywords: Exercise; Depression; Sports.

\section{RESUMO}

Introdução: O exercício físico tem se tornado um método comum, tanto no país quanto no exterior, na psicoterapia e para a saúde mental. Objetivo: Observar a situação e as características atuais do exercício físico e dos transtornos depressivos e examinar o efeito do exercício físico nos transtornos depressivos do corpo humano. Métodos: $O$ artigo compara e analisa a relação entre o exercício físico em humanos e o nível de depressão e autoestima corporal da perspectiva psicológica. Resultados: A incidência de depressão émais elevada. Existem diferenças significativas entre a atitude quanto ao exercício físico e o grau de depressão nos três tipos de sujeito do estudo. O exercício físico leva ao alívio da depressão. Conclusão: O exercício físico é uma das maneiras mais eficazes para melhorar o estado de depressão no corpo humano. O efeito do exercício não tem relação com a escolha de um método de exercício específico. Nível de evidência ll; Estudos terapêuticos - investigação de resultados de tratamento.

Descritores: Exercício físico; Depressão; Esportes.

\section{RESUMEN}

Introducción: El ejercicio físico se ha convertido en un método común, tanto en China como en el exterior, en la psicoterapia y para la salud mental. Objetivo: Observar la situación y las características actuales del ejercicio físico y de los trastornos depresivos y examinar el efecto del ejercicio físico en los trastornos depresivos del cuerpo humano. Métodos: El artículo compara y analiza la relación entre el ejercicio físico en humanos y el nivel de depresión y autoestima corporal de la perspectiva psicológica. Resultados: La incidencia de depresión es más elevada. Existen diferencias significativas entre la actitud cuanto al ejercicio físico y el grado de depresión en los tres tipos de sujeto del estudio. El ejercicio físico lleva al alivio de la depresión. Conclusión: El ejercicio físico es una de las maneras más eficaces para mejorar el estado de depresión en el cuerpo humano. El efecto del ejercicio no tiene relación con la elección de un método de ejercicio específico. Nivel de evidencia Il; Estudios terapéuticos - investigación de resultados de tratamiento.

Descriptores: Ejercicio físico; Depresión; Deportes.

\section{INTRODUCTION}

Depressive disorder in the elderly refers to a mental disorder whose first onset age is $\geq 60$ years old, and the primary clinical manifestation is a long-lasting melancholic mood. This is the second biggest killer to destroy the health of the elderly after cardiovascular disease. Once the illness is mild, the patient is enveloped by feelings of loneliness, helplessness, and worthlessness. In severe cases, it may cause disability and even cause the patient to commit suicide. ${ }^{1}$ Therefore, attention to the health of the elderly cannot ignore the elderly depression. Previous studies on depression interventions focused on drug treatment and supplemented with psychotherapy. However, these traditional therapies are often not as effective as younger patients due to the unique physiological and psychological characteristics of the elderly. In recent years, many scholars abroad have discussed the effect of physical exercise on the intervention of depressed patients. Still, a small number of studies have been conducted on elderly depressed patients. ${ }^{2}$ This is convenient 
to provide a scientific basis for effectively preventing and overcoming depression in the elderly and giving full play to the "heart-building" function of physical exercise.

\section{METHODS}

\section{General information}

This study randomly surveyed older people over 60 years old in a particular city. We sent out 300 questionnaires and received 270 valid questionnaires. Among them, 145 are males, accounting for $53.1 \%$, and 125 are females, accounting for 45.8\%. (Table 1).

\section{Research methods}

This study uses questionnaire surveys and interviews to conduct investigations. The questionnaires are the self-compiled "Physical Exercise Scale for the Elderly" and Brink's "Concise Depression Scale for the Elderly." The two questionnaires are combined into one. The entire measurement process takes about 20 minutes. The Physical Exercise Scale for the Elderly includes a total of 14 questions. ${ }^{3}$ We investigate the physical exercise of the elderly from seven dimensions: attitude and motivation of physical exercise, item selection, intensity, frequency and duration, influencing factors, exercise methods, and future expectations.

The Concise Scale for Depression in the Elderly (GDS-s) compiled by Brink et al. is a condensed form of the original Depression Scale for the Elderly. The depression scale created and standardized for the elderly has a higher compliance rate than other depression scales in clinical evaluation. This is even more obvious for older people. This scale is a self-report scale, which is composed of 4 groups of specific states of depression. It can effectively reflect the degree and changes of depressive symptoms and is especially suitable for general hospitals to find patients with depressive disorders. ${ }^{4}$ The scale has high reliability and validity. The sensitivity is $88 \%$ to $93 \%$. Cronbach's coefficient is 0.82 ; the split-half reliability is 0.75 . In addition, the questionnaire also includes some demographic variables. The variables involved 7 items, including gender, age, marital status, living status, previous occupation, education level, and self-perceived health status.

\section{Statistical processing}

We used SPSS12.0 statistical software to perform a one-way analysis of variance, $\times 2$ test, multiple comparison tests, and multiple response contingency table analysis on all data. ${ }^{5}$ Solve the Denavit-Hartenberg spatial distribution vector of the human body posture distribution in sports. We introduce the wrong action primitives in sports into the closed curve $C$, and at the same time, we use a smooth time delay function to denote it as $C=\{(x, y) \in \Omega: \varphi(x, y)=0$. In the active area of the contour line, the article uses the background image $B$ of the sports scene set to obtain the wavelet multidimensional scale decomposition coefficient of the sports wrong action image (the coefficient $v$ is usually 0 , and the value is 0 here):

$$
\begin{aligned}
& E^{c v}\left(c_{1}, c_{2}\right)=\mu \int_{\Omega} \delta(\varphi(x, y))|\nabla \varphi(x, y)| d x d y+ \\
& \lambda_{1} \int_{\Omega}\left|I-c_{1}\right|^{2} H(\varphi(x, y)) d x d y+ \\
& \lambda_{2} \int_{\Omega}\left|I-c_{2}\right|^{2}(1-H(\varphi(x, y)) d x d y
\end{aligned}
$$

Table 1. Participants

\begin{tabular}{c|c|c|c|c|c}
\hline \multicolumn{2}{c|}{ Exercise location } & Public places & Community & Hospital & Total \\
\hline \multirow{4}{*}{$\begin{array}{c}\text { Age } \\
\text { (year old) }\end{array}$} & $60-64$ & $51(18.9)$ & $12(4.4)$ & $7(2.6)$ & $70(25.9)$ \\
\cline { 2 - 6 } & $65-69$ & $53(19.6)$ & $7(2.6)$ & $5(1.9)$ & $65(24.1)$ \\
\cline { 2 - 6 } & $70-74$ & $72(15.6)$ & $14(5.2)$ & $8(3.0)$ & $64(23.7)$ \\
\cline { 2 - 6 } & $75-79$ & $23(8.5)$ & $8(3.0)$ & $8(3.0)$ & $39(14.4)$ \\
\cline { 2 - 6 } & $80-84$ & $11(4.1)$ & $11(4.1)$ & $6(2.2)$ & $28(10.4)$ \\
\cline { 2 - 6 } & $>85$ & 0 & $2(0.7)$ & $2(0.7)$ & $4(1.5)$ \\
\cline { 2 - 6 } & Total & $180(66.7)$ & $54(20.0)$ & $36(13.3)$ & $270(100.0)$ \\
\hline
\end{tabular}

$H(z)$ and $\delta(z)$ respectively represent the module sub-blocks of 3D image visual modeling of sports actions. We use the block matching method to divide the wrong actions in sports into $(W \mid 2) \times(H \mid 2)$ sub-blocks. ${ }^{6}$ We use the difference matching method to obtain the multidimensional wavelet scaling function of sports wrong actions as follows:

$$
\begin{aligned}
& E^{L B F}\left(\varphi, f_{1}, f_{2}\right)=\mu \int \frac{1}{2}(\nabla \varphi \mid-1)^{2} d x+v \llbracket \text { Length }(C)+ \\
& \lambda_{1} \int\left[K_{\sigma}(x-y)\left|I-f_{1}(x)\right|^{2} H(\varphi) d y\right] d x+ \\
& \lambda_{2} \int\left[K_{\sigma}(x-y)\left|I-f_{2}(x)\right|^{2}(1-H(\varphi) d y] d x\right.
\end{aligned}
$$

$\lambda_{1}, \lambda_{2}, \mathrm{v}, \mu$ is a non-negative constant. $K_{\sigma}$ is the standard deviation of the two boxes of edge contour matching and feature fusion. $\sigma$ is the weight coefficient. By selecting the size of the weight coefficient $\sigma$, the edge contour feature amount of the sports wrong action image is adjusted. The image is decomposed into two regions $R_{1}$ and $R_{2}$ in the three-dimensional data field. We calculate the sampling point type matching point neighborhood combined with the gradient information extraction method of the local image to reconstruct the image.

\section{RESULTS}

\section{Status and characteristics of physical exercise of the elderly}

Most of the subjects in this group had a relatively positive attitude towards physical exercise. The number of patients who liked and liked physical exercise very much accounted for $82.5 \%$. The exercise plan is strong, and the number of patients who insist on exercising after the plan accounts for $65.8 \%$. The number of patients who wanted to try exercise accounted for $15.3 \%$. At the same time, the enthusiasm for exercise is higher, and the exercise frequency is more frequent. The number of patients who exercise more than 3 times a week amounts to $82.6 \%$. This shows that the elderly has a more vital awareness of exercise and fitness, a more positive attitude, basic scientific methods, and good results. ${ }^{7}$

\section{Status and characteristics of depression in the elderly}

The detection rate of depression in this group was as high as $25.3 \%$. Among them, the number of severely depressed patients accounted for $6.6 \%$, and the number of mildly depressed patients accounted for $18.7 \%$ (Table 2). We performed an analysis of variance and $x 2$ test on the data and found that different living environments and demographic variables significantly impact depression. The specific performance is as follows:

\section{The impact of different living environments on the degree of depression in the elderly}

The analysis of variance showed significant differences in the degree of depression among the elderly in different living environments. ${ }^{8}$ The depression in public places was the lowest, and the depression in hospitals was the highest.

\section{The influence of demographic variables on the degree of depression in the elderly}

Analysis of variance showed that marital status, health status, and the living conditions of the surviving spouse all have a significant impact on the degree of depression. Their values are $\mathrm{F}=6.736, \mathrm{P}<0.01$;

Table 2. Incidence of depression in 270 subjects.

\begin{tabular}{c|c|c|c|c}
\hline & Public places & Community & Hospital & Total \\
\hline No depression & $145(53.1)$ & $37(13.6)$ & $22(8.1)$ & $204(74.4)$ \\
\hline Mild depression & $30(11.0)$ & $14(5.1)$ & $7(2.6)$ & $51(18.7)$ \\
\hline Severe depression & $7(2.6)$ & $4(1.5)$ & $7(2.6)$ & $18(6.6)$ \\
\hline Total & $182(66.7)$ & $55(20.1)$ & $36(13.2)$ & $273(100.0)$ \\
\hline
\end{tabular}


$F=9.189, P<0.001$ and $F=5.258, P<0.001$. The worse the marital status and health status, the higher the degree of depression. The incidence of mild depression of the surviving spouse was 14.8\%, and the incidence of severe depression was $2.1 \%$. The incidence of both mild and severe depression among widows was $18.0 \%$. The prevalence of divorced persons is as high as 100\%.

The analysis of variance also showed that although the difference in depression among people with different education levels is not significant on the whole. However, the t-test found that the depression scores of seniors with high school or technical secondary school education were lower than those with lower elementary school and junior high school education. In addition, the degree of depression of women is slightly higher than that of men, but there is no significant difference between the two.

\section{The effect of physical exercise on depression in the elderly}

The analysis of variance showed that the attitude, intensity, frequency, method, length of time, experience after exercise, and enthusiasm of exercise plan of physical exercise significantly impact depression in the elderly. The more active the elderly exercise attitude, the more moderate the intensity, the more times, the longer the time, the better the experience after exercise, and the lower the degree of depression. The depression degree of the more exercise-like group was significantly lower than that of the indifferent group and the disgusting group. Those who exercise 3 to 4 times a week are significantly more depressed than those who exercise 5-6 times or more than 7 times a week. The depression degree of the group who exercised less than $0.5 \mathrm{~h}$ each time was significantly higher than that of the group of 1-2h, 2-3h, and more than $3 \mathrm{~h}$. The depression degree of those who had activity partners was significantly lower than those who exercised alone.

\section{DISCUSSION}

Although the detection rate of depression in the elderly is not uniform, depression is more common in the elderly. This has serious adverse effects on the elderly. Therefore, we should attach great importance to and strengthen the prevention and intervention of depression in the elderly. This study also shows that women are slightly more depressed than men. This is consistent with the results of previous studies. This suggests that special attention should be paid to female elderly groups in the specific preventive intervention process to improve the intervention effect.

Finding suitable and feasible methods to prevent and intervene depression in the elderly has always been one of the focus issues of geriatrics, health care, psychology, and other disciplines. Previous studies have primarily focused on drug therapy and psychotherapy, and relatively few involved physical exercise therapies. Participating in physical exercise can effectively prevent and reduce depression and an economical, simple, and widely adaptable intervention. Some scholars analyzed 14 studies on physical exercise therapy for depression and found that the effect of physical exercise therapy is much better than that of placebo therapy and non-treatment. Some scholars have analyzed that physical exercise can effectively reduce the depressive symptoms of moderately elderly depressed patients in an extensive range in the short term. Some scholars found that long-term exercise can effectively alleviate depression symptoms and further explored two psychological mechanisms that affect the antidepressant effect of exercise. There are very few studies on the influence of physical exercise methods or sports events on depression. Some scholars can effectively reduce depression symptoms for 20 weeks of weightlifting without coaching. Some scholars have found that although physical exercise therapy is equivalent to psychotherapy and antidepressant therapy, the cost of the latter two therapies is relatively high. Some scholars respectively reviewed related research and affirmed the intervention effect of physical exercise on depression. However, relatively few studies on elderly patients and related studies in China are even rarer.

This study shows that physical exercise has a significant impact on depression in the elderly. Those older adults who actively engage in physical exercise and take appropriate and effective ways to exercise are relatively low in depression. On the contrary, the degree of depression is relatively high. Therefore, to effectively intervene in depression in the elderly, the role of physical exercise cannot be ignored. Therefore, it is necessary to strengthen further the research on the intervention of physical exercise on the elderly depression and at the same time promote the practical work of physical exercise intervention on the elderly depression.

According to the results of this survey, we suggest that the elderly should develop a positive attitude towards physical exercise and participate in physical exercise activities in public places. The elderly takes active exercise measures on this basis. If you insist on participating in exercise every day, the time of each exercise should not be too short. Strive to be accompanied by a partner every time. Control the intensity of exercise to make the body feel comfortable after exercise and feel comfortable. In the long run, developing good habits can effectively prevent depression in the elderly.

\section{CONCLUSION}

This study is just a preliminary baseline survey only to understand the current status of physical exercise and depression in the elderly and explore the relationship between the two. As for how to prevent and intervene depression in the elderly and promote the mental health of the elderly through physical exercise, further research is needed.

The author declare no potential conflict of interest related to this article

AUTHORS' CONTRIBUTIONS: This paper is independently completed by the author, Linyan Dang: data analysis and article writing

\section{REFERENCES}

1. Gorham LS, Jernigan T, Hudziak J, Barch DM. Involvement in Sports, Hippocampal Volume, and Depressive Symptoms in Children. Biol Psychiatry Cogn Neurosci Neuroimaging. 2019;4(5):484-492. doi: 10.1016/j.bpsc.2019.01.011.

2. Ströhle A. Sports psychiatry: mental health and mental disorders in athletes and exercise treatment of mental disorders. Eur Arch Psychiatry Clin Neurosci. 2019;269(5):485-498. doi: 10.1007/ s00406-018-0891-5.

3. Pascoe MC, Parker AG. Physical activity and exercise as a universal depression prevention in young people: A narrative review. Early Interv Psychiatry. 2019;13(4):733-739. doi: 10.1111/eip.12737.

4. McCarty CA, Zatzick D, Hoopes T, Payne K, Parrish R, Rivara FP. Collaborative care model for treatment of persistent symptoms after concussion among youth (CARE4PCS-II): Study protocol for a randomized, controlled trial. Trials. 2019;20(1):567. doi: 10.1186/s13063-019-3662-3.

5. Hallgren M, Dunstan DW, Owen N. Passive Versus Mentally Active Sedentary Behaviors and Depression. Exerc Sport Sci Rev. 2020;48(1):20-27. doi: 10.1249/JES.0000000000000211.

6. Schuch FB, Stubbs B. The Role of Exercise in Preventing and Treating Depression. Curr Sports Med Rep. 2019;18(8):299-304. doi: 10.1249/JSR.0000000000000620.

7. López-Torres Hidalgo J; DEP-EXERCISE Group. Effectiveness of physical exercise in the treatment of depression in older adults as an alternative to antidepressant drugs in primary care. BMC Psychiatry 2019;19(1):21. doi: 10.1186/s12888-018-1982-6.

8. Gupta A, Summerville G, Senter C. Treatment of Acute Sports-Related Concussion. Curr Rev Musculoskelet Med. 2019;12(2):117-123. doi: 10.1007/s12178-019-09545-7. 